\title{
Segmental lineage restrictions in the chick embryo spinal cord depend on
}

\section{the adjacent somites}

\author{
CLAUDIO D. STERN ${ }^{1}$, KAREN F. JAQUES ${ }^{2}$, TIT-MENG LIM ${ }^{3}$, SCOTT E. FRASER ${ }^{4}$ and \\ ROGER J. KEYNES ${ }^{2}$ \\ 1 Department of Human Anatomy, South Parks Road, Oxford OXI 3QX, UK \\ 2Department of Anatomy, Downing Street, Cambridge CB2 3DY, UK \\ ^Department of Zoology, National University of Singapore, Singapore 0511 \\ * Department of Physiology and Biophysics, University of California, Irvine, California 92717, USA
}

\begin{abstract}
Summary
We have investigated whether the developing spinal cord is intrinsically segmented in its rostrocaudal (anteroposterior) axis by mapping the spread of clones derived from single labelled cells within the neural tube of the chick embryo. A single cell in the ventrolateral neural tube of the trunk was marked in situ with the fluorescent tracer lysinated rhodamine dextran (LRD) and its descendants located after two days of further incubation. We find that clones derived from cells labelled before overt segmentation of the adjacent mesoderm do not respect any boundaries within the neural tube. Those derived from cells marked after mesodermal segmentation, however, never cross an invisible boundary aligned with the middle of each somite, and tend to
\end{abstract}

be elongated along the mediolateral axis of the neural tube.

When the somite pattern is surgically disturbed, neighbouring clones derived from neuroectodermal cells labelled after somite formation behave like clones derived from younger cells: they no longer respect any boundaries, and are not elongated mediolaterally. These results indicate that periodic lineage restrictions do exist in the developing spinal cord of the chick embryo, but their maintenance requires the presence of the adjacent somite mesoderm.

Key words: cell lineage, segmentation, spinal cord, neural tube, neuromeres, chick embryo, somites, fluorescent dextrans.

\section{Introduction}

In the accompanying paper ( $\operatorname{Lim}$ et al. 1991), the role of segmentation in avian spinal cord development is analysed by examining the spatiotemporal patterns of cell division and neuronal differentiation. It is concluded that the myelomeres, or macroscopic segments of the spinal neural tube, are not matched by segmental patterns of cell division and differentiation. Instead, they are likely to result from mechanical moulding of the neuroepithelium by the adjacent mesodermal somites. It remains possible, nevertheless, that spinal cord segmentation is detectable in the form of periodic lineage restrictions, or boundaries, that limit the rostrocaudal (anteroposterior) spread of clonal descendants of precursor cells to single myelomeres. Whilst myelomeres show the same periodicity as the adjacent somitic mesoderm, it is not immediately obvious whether they are aligned with the somites or out of phase with them by a half-segment. This latter possibility is consistent with the existence of an intrasomitic fissure (von Ebner's fissure; see Stern and Keynes, 1987).
Lineage restriction boundaries in the developing hindbrain epithelium have been described recently, and these match the overt segmental pattern of hindbrain rhombomeres (Fraser et al. 1990). A similar situation exists in the diencephalon of the chick embryo, where lineage restriction boundaries separate the four diencephalic neuromeres (Figdor and Stern, 1991). In this study, we report the existence of periodic restriction boundaries in the developing spinal cord. Microsurgical manipulations have been carried out to test directly whether they reflect intrinsic segmentation of the neural tube, or whether they result instead from an interaction with the adjacent somites.

\section{Materials and methods}

\section{Embryo preparation}

The embryo within a fertile hen's egg, incubated for about 36-50 h (stages 9-14 of Hamburger and Hamilton, 1951), was made visible by cutting a $1.5 \mathrm{~cm}$ square window in the shell, and floated to the level of the shell with calcium- and magnesium-free Tyrode's saline (CMF). A small volume of Indian ink solution in CMF was injected under the blastoderm 
to aid in its visualisation, and the whole egg placed under a Zeiss microscope equipped with epifluorescence optics and an Olympus 20x ultra-long working distance objective.

\section{Intracellular injection of $L R D$}

Injections were performed using a fine glass micropiperte pulled from aluminosilicate capillaries with internal filament $(1.2 \mathrm{~mm}$ outer diameter, $0.9 \mathrm{~mm}$ internal diameter; $\mathrm{A}-\mathrm{M}$ Systems Inc.), pulled to a fine tip with a two-stage vertical microelectrode puller (Ealing). The tip of the pipette was first filled with a $10 \mathrm{mg} \mathrm{m}^{-1}$ solution of Lysinated Rhodamine Dextran (LRD; $M_{\mathrm{r}} 10000$; Molecular Probes, Inc.) and then back-filled with $1.2 \mathrm{~m} \mathrm{KCl}$; filled electrode resistances ranged from 60 to $100 \mathrm{M} \Omega$. This arrangement allows recording and injection through the same electrode, which is necessary to determine when the electrode has penetrated a cell.

Recording and injection were done using a Neurolog NL102G preamplifier and headstage (Digitimer) and the output visualised through a digital storage adaptor (DSA51L; Thurlby) and Hitachi oscilloscope V222,20 MHz. Injection of dye was achieved iontophoretically, using 2-8nA pulses (1 $\mathrm{Hz}, 500 \mathrm{~ms}$ duration) of current generated by a period generator (NL304; Digitimer) and digital width controller (NL401; Digitimer) fed into a current injection module of the NL102G preamplifier. The use of pulses of current allows the membrane resistance and resting potential to be monitored during the injection, which can be used to assess the state of the cell being labelled.

Movement of the electrode for impalement was controlled with a Significat SCAT-01e computer-controlled stepper motor (Digitimer) mounted on a 3-axis micromanipulator. The Significat allowed movement of the electrode along its axis in steps of $2 \mathrm{~mm}$.

Using the methods described above, a single ventrolateral neural tube cell was marked with LRD in cach of a total of 331 embryos. The injections were performed at various rosirocaudal levels of the neural tube, the most caudal level being opposite the caudal segmental plate mesoderm and the most rosiral level being opposite somites that had differentiated into sclerotome and dermomyotome (about 12 segments rostral to the most recently segmented somite) (see Fig. 1).

After injection, the electrode was withdrawn rapidly from the cell, and the labelled cell was observed using epjfluorescence optics to confirm that a single cell had been labelled in the correct region of the embryo. The egg was then sealed with $P V C$ tape and returned to the incubator at $38^{\circ} \mathrm{C}$ to develop for a further $36-48 \mathrm{~h}$. After this period of further incubation, the embryo was explanted and fixed for 30-60 min in buffered formol saline ( $\mathrm{pH} 7,0$ ), washed in phosphatebuffered saline (PBS, $\mathrm{pH} 7.4$ ), eviscerated and bisected along the midline of the neural tube. It was then cleared and mounted between coverslips in Gelvatol (14\% polyvinyl alcohol $20 / 30$ [Fisons] containing $8.5 \mathrm{mg} \mathrm{m}^{-1}$ diazobic yclooc. tane [DABCO, Addrich] as an anti-quenching agent, $30 \%$ glycerol and $350 \mathrm{mg} \mathrm{ml}^{-p}$ sodium azide as preservative in a PBS base, pH 6.8). Alternatively, the tissue was mounted between coverslips in a mixture of glycerol ( 9 parts) and $10 \times$ PBS (1 part), and the pH adjusted to 7.4

\section{Examination of clones}

Clones were observed in one or more of three different ways: (a) by conventional fuorescence microscopy and photography; (b) using a Silicon Intensifier Target (SIT) camera and image analyzer and (c) by confocal scanning laser microscopy.

Conventional microscopy

An Olympus Vanox-T microscope equipped with epiffor-

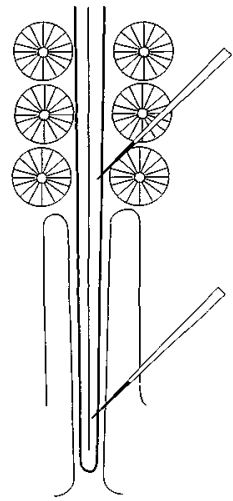

Fig. 1. Diagram showing the two regions in which injections of LRD were performed. In one set of experiments, the dye was injected into a single ventral neural tube cell opposite somites that had already formed (upper part of diagram); in another, ventral neural tube cells opposite the caudal segmental plate mesoderm were filled with dye (lower part of diagram).

escence optics with $10 \times$ and $20 \times$ UVFL fluorescence-free objectives. A $200 \mathrm{~W}$ high pressure mercury lamp was used. Photography was done using Kodak T-MAX400 (black-andwhite) or Fuji 1600P (colour transparency) film.

\section{SIT Camera and Image analysis}

In some cases, clones were examined under the Olympus microscope using a Silicon Intensifier Target (SIT) camera (LTC1160SIT, Custom Camera Designs, Wells) and image analysis system (Seescan $I 3000$; resolution $256 \times 256$ pixels, 256 grey levels). Imaging at this stage was performed by averaging 8 trame captures and subtracting the background due to camera tube noise, which had been stored at the start of each session and at about $1 \mathrm{~h}$ intervals thereafter. Averaged images were stored on magnetic tisc or video tape; for each frame stored, a control frame for autofluorescence was also scored, acquired as described above but using fluorescein filters instead of a rhodamine set. In most cases, additional contrast enhancement was performed for photography: each frame was retrieved from the magnetic disc or tape, and a $\gamma$ correction with a factor of 1.6 applied (an exponential filter which has the effect of increasing contrast in the pixels in bright areas without affecting those in dark regions). After $\gamma$ correction, a 'sharpen' algorithm was appljed, which is a twodimensional filter maximising the grey-level change at points at which neighbouring pixels change from dark to white rapidly. This algorithm has the effect of enhancing the edge of labelled cells (and is therefore similar to 'edge detect' algorithms). Although its effect on the image is only barcly 
noticeable, it gives the impression of improved 'focus'. Photographs were then obtained from the screen of a CUB RGB video monitor using a $35 \mathrm{~mm}$ camera. In some cases, the clones were highlighted using a pseudo-colour palette.

\section{Confocal scanning laser microscopy}

A BioRad MRC500 was used, fitted with a $25 \mathrm{~mW}$ argon ion laser. Two images were obtained from each specimen; one using transmitted light and the other with laser fluorescence (excitation at $514 \mathrm{~nm}$ ). The two images were then 'merged' using the MRC500 software; the fluorescence image was displayed with a red palette whilst the transmitted light image was shown in blue.

\section{Microsurgery}

In order to misalign the somites with respect to their corresponding myelomeres, two microsurgical operations were performed immediately after labelling a single ventral neural tube cell opposite the middle of the newest (most caudal) somite with LRD in a total of 29 embryos (Fig. 2).

In 12 of these embryos, the newest somite and 2-3 presumptive segments of segmental plate mesoderm were removed. In the remaining 17 embryos, the newest 3-4 somites and a piece of rostral segmental plate 1-2 presumptive somites in length were removed and replaced with a piece

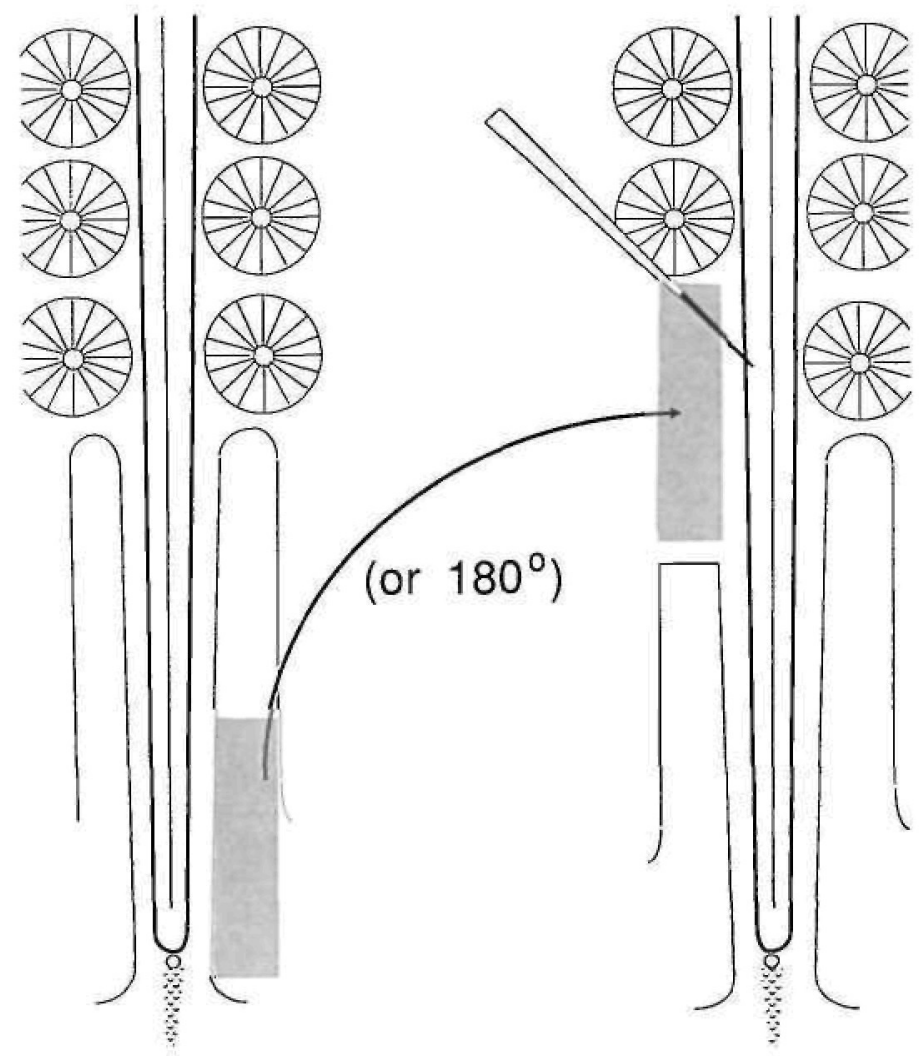

Fig. 2. Diagram summarising the operations performed on the somitic mesoderm. First, LRD was injected into a single ventral neural tube cell opposite the middle of the most recently segmented somite (upper right part of diagram). Then, the ipsilateral somite opposite the site of injection, together with a portion of unsegmented mesoderm were excised. Finally, the excised tissue was replaced with a portion of caudal segmental plate from a similarly staged donor embryo, either in the same orientation or after $180^{\circ}$ rotation about its rostrocaudal axis. of contralateral caudal segmental plate which had been rotated by $180^{\circ}$ about its rostrocaudal axis (Fig. 2).

After these operations, which were performed with Week microsurgical knives $\left(15^{\circ}\right.$ angle $)$ in 0.08-0.1\% trypsin (1:250, Difco) in CMF, the embryos were washed briefly in CMF and the shells sealed for incubation at $38^{\circ} \mathrm{C}$. After $36-48 \mathrm{~h}$ postoperative incubation, the embryos were fixed as described above and mounted in toto (without bisecting) for examination in a fluorescence microscope. Images from these embryos were obtained either by conventional microscopy using a Zeiss Axiophot microscope and photographed on Kodak Ektachrome 400 film, or with a Zeiss Universal microscope fitted with a SIT camera and image analyzer (Imaging Technology 151 using the Vidlm software written by Drs S. E. Fraser J. Stollberg and G. Belford) and stored using an optical magnetic disc recorder.

\section{Results}

Clones derived from rostral injections (Fig. 3A-D) In 177 cases, lysinated rhodamine dextran (LRD) was injected into a single neuroepithelial cell in the ventrolateral aspect of the neural tube of stage 11-14 embryos, opposite regions of the trunk where somites had already formed in the adjacent mesoderm. Embryos were fixed after $36-48 \mathrm{~h}$ of subsequent incubation. Fluorescent clones were found in 83 cases. The majority of the clones spanned a rostrocaudal distance equivalent to $1 / 4-1 / 3$ of one somite (20-40 [ im) and were usually twice as large $(40-80, \mathrm{um})$ in mediolateral extent (Fig. 3B,D). Clones were classified according to whether they spread across a line opposite the adjacent inter-somitic boundary and/or the adjacent intrasomitic boundary (von Ebner's fissure). Of these 83 clones, clone size and position could be recorded accurately in 72 cases. Out of these, 19 clones crossed the line opposite the intersomitic space, while none crossed the level opposite the middle of the ipsilateral somite (von Ebner's fissure), despite the fact that 49 clones ( $68 \%$ of clones recorded) reached this border. A few of the clones were so small as not to reach either border $(16 / 72 ; 22 \%)$. It is therefore unlikely that the difference in the behaviour of clones at the two lines is due to chance $\left(^{\wedge}\right.$ test, 1 d.f.; $\mathrm{P}<0.001$ ).

Six of the clones included cells within the floor plate of the developing spinal cord; in each of these cases, labelled cells spread extensively (more than 5 somite lengths, or $550^{\wedge} \mathrm{m}$ in rostrocaudal extent) within the floor plate. Three further clones contained neural crest cells, which could be recognized because they had emerged from the tube and some of them were contained within the rostral halves of the adjacent sclerotomes. These 9 clones were not included in the analysis of rostrocaudal spread of clones summarised above.

Clones varied in size between 1 ( 2 cases) and about 500 cells (corresponding to 9 symmetrical mitotic divisions), but most of them (56 clones) comprised 30-120 cells (5-7 divisions). Smaller clones were composed predominantly of neurons (axons and sometimes growth cones were visible), while the larger clones invariably contained a majority of cells. of non- 
neuronal cells, presumably glial cells. All types of neurons were seen, as identified by the direction of their axons: commissural (axon crossing ventral midline), association (axon extending rostrocaudally within the tube) and motor (axon leaving neural tube and entering the rostral half of the adjacent sclerotome). As described previously (Stern et al. 1988) individual clones often contained a mixture of different cell phenotypes.

\section{Clones derived from more caudal injections} (Fig. 3E,F)

In 154 cases, LRD was injected into a single neuroepithelial cell in the ventrolateral aspect of the neural tube of stage 9-13 embryos, opposite regions of the trunk where somites had not yet formed from the adjacent mesoderm. After $36-48 \mathrm{~h}$ further incubation of these embryos, 68 clones were recovered. The clones spanned a rostrocaudal distance of up to 3 somites (from 30 to $300, \mathrm{um}$ ), and a mediolateral extent of $30-80^{\wedge} \mathrm{m}$. Because of their considerable rostrocaudal spread, clones tended to cross the intersegmental line (32 cases) and the line opposite the middle of the somite (34 cases): many crossed both boundaries (Fig. 3E).

Of the 34 clones that crossed the line opposite the middle of the somite, 28 arose from a parent cell that had been labelled opposite the youngest regions (caudal $1 / 3-1 / 2$ ) of the segmental plate. The remaining 6 clones arose from cells labelled while they were adjacent to the rostral half of the segmental plate.

As was the case in embryos in which the neural tube cell was labelled in older, more rostral regions, clones ranged considerably in size (from 8 to more than 500 cells). Again, all cell types were represented among the clones. They included neural crest cells ( 2 cases), glial cells and all types of neurons. In these embryos, neurons were often present in some of the larger clones (those containing more than 100 cells).

\section{Clones derived from rostral injections in operated embryos (Fig. 4)}

To investigate whether cells derived from progenitors opposite the middle of a newly formed somite respect an invisible neural tube boundary at this level, embryos in which a single ventrolateral neuroepithelial cell had been labelled were operated as shown in Fig. 2 to disturb the segmental pattern of the adjacent mesoderm.

In those embryos in which the somites and rostral segmental plate opposite the labelled cell had been removed and the embryos incubated for a further $36-48 \mathrm{~h}$, the region of the operation was devoid of segmented mesoderm. In most of the embryos, the more lateral mesoderm had filled the gap produced by the operation. Eleven clones were recovered from these embryos. Of these, 6 crossed the line opposite the middle of the somite on the contralateral (unoperated) side of the embryo. Five of these 6 clones had expanded along the rostrocaudal axis, spanning a region longer than one mesodermal segment, resembling the behaviour of clones arising from cells labelled opposite the caudal segmental plate in unoperated embryos (see above).

In those embryos in which the somitic mesoderm opposite the labelled cell had been replaced with a graftof caudal segmental plate mesoderm (Fig. 2), somites had formed in the region of the operation but these were invariably out of phase with the contralateral (unoperated) somites. Six clones were recovered from these embryos. Of these, 4 crossed the line opposite the middle of the somite on the contralateral side of the embryo (Fig. 4). Interestingly, the clones were orientated mediolaterally, like clones derived from injections at more rostral levels in unoperated embryos (e.g. Fig. 3B).

In conclusion, therefore, clones derived from neuroepithelial cells labelled in regions rostral to the most recently formed somite respect an invisible boundary that lies opposite the middle of each somite. However, the continued presence of the somite mesoderm is required for this lineage restriction to be maintained.

\section{Discussion}

We have shown that the descendants of single cells in the ventrolateral neuroepithelium of the spinal cord of the chick embryo respect an invisible line opposite the middle of the adjacent somite (von Ebner's fissure). The trunk neural tube is therefore subdivided by lineage restriction boundaries, defining units that extend from a level opposite the middle of one somite to the middle of the next. The restrictions appear concurrently with the process of segmentation of the neighbouring somitic mesoderm, and it was therefore important to ask whether they depend on the continued presence of somites. By disturbing the pattern of somites, it was found that these lineage restrictions are not an autonomous property of the neural tube: they require the presence of the somites for their maintenance.

A recent study using retrovirus-mediated transfer of the 3 -galactosidase gene (lacZ) to follow the lineage of spinal cord cells in the chick embryo (Leber et al. 1990) found that clones tend to spread perpendicular to the rostrocaudal axis of the embryo. These findings agree with the present study: cells marked with LRD while opposite segmented mesoderm generate clones that tend to spread mediolaterally. It may be significant that Leber et al. (1990) did not observe clones spreading along this axis; this may indicate that their technique fails to label cells at stages of development earlier than those located opposite segmented mesoderm. Perhaps younger cells are refractory to retrovirus infection, or they may become infected at a much lower frequency than older cells.

Our results demonstrate, in a vertebrate embryo, lineage restrictions respecting a line other than a morphologically visible boundary restricting cell migration (such as the border between adjacent somites or the regions of cell alignment between rhombomeres in the hindbrain or between diencephalic neuromeres; see 

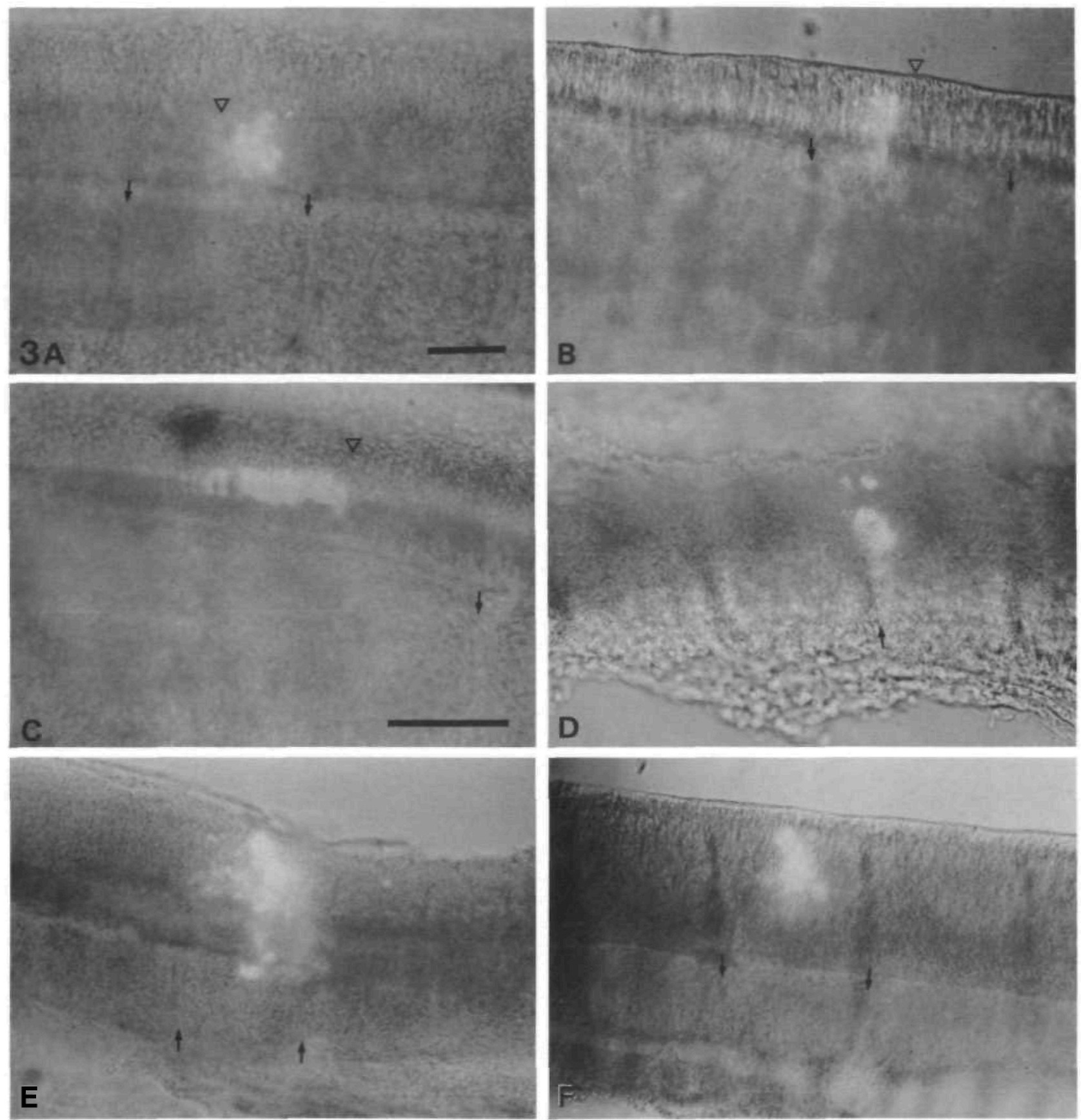

Fig. 3. Results obtained from LRD injections into the ventral neural tube in unoperated embryos. A-D summarise the results obtained from injections into the tube opposite somites that had already formed and E-F show the results obtained when cells were injected in more caudal regions. All photographs are double-exposures of whole-mounted embryos, using fluorescence to reveal the clone and bright field to reveal the somite boundaries, Intersomitic borders are marked with arrows. (A) An example of a neural tube clone which reaches von Ebner's fissure of the adjacent somite (open arrowhead) from its rostral (right) side. (B) Example of a mediolaterally elongated clone. Note that the side of the clone nearest von Ebner's fissure of the somite opposite (open arrowhead) appears as a straight edge, whilst cells in the more distant side of the clone are more disperse. (C) An example of a clone reaching the region opposite von Ebner's fissure (open arrowhead) from the caudal (left) side. Again, the clone ends abruptly at this level. (D) Example of a clone which crosses the region opposite the border between two adjacent somites. (E) This clone, resulting from an injection opposite the caudal

unsegmented mesoderm, extends over a considerable rostrocaudal distance and crosses both an intersomitic border and von Ebner's fissure. (F) Example of a clone, again resulting from a caudal injection, which crosses the region opposite von Ebner's fissure. Scale bars, $50^{\wedge} \mathrm{m}$. B,D,E,F: same magnification as A. 

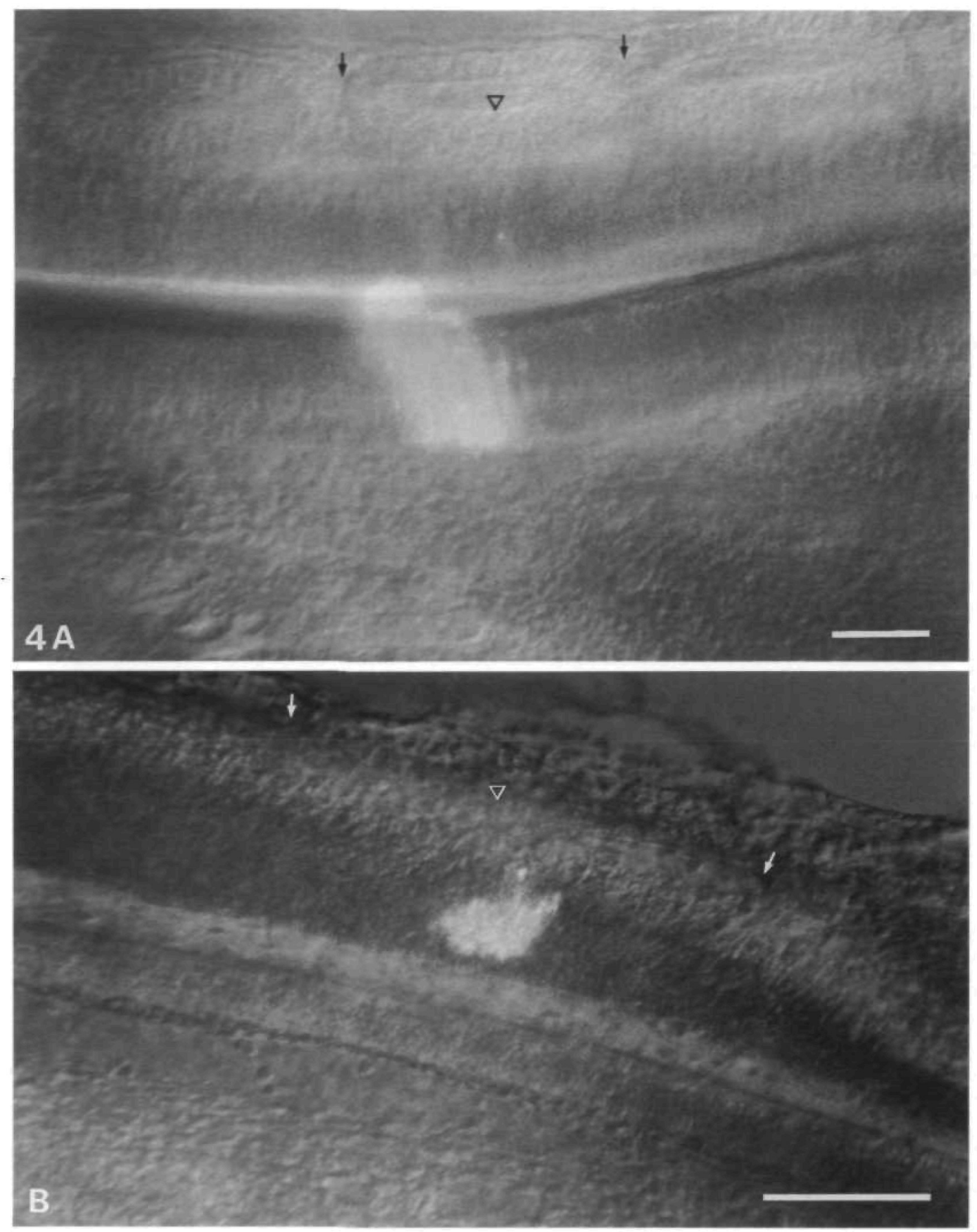

Fig. 4. Two examples of clones resulting from injections opposite the middle of an already formed somite in embryos operated to disrupt the metameric organisation of the adjacent mesoderm. Whole mounts, double exposures showing the clone under fluorescence and the embryo by bright-field microscopy. Arrows point to the inter-somite borders. (A) Clone that extends from the intersomitic border (left) and crosses von Ebner's fissure (open arrowhead) of the contralateral (unoperated) somite. (B) Clone crossing the region of neural tube opposite the von Ebner's fissure (open arrowhead) of the contralateral somite. Scale bars, 50 jum. 
Stern etal. 1988; Keynes and Stern, 1988; Lumsden and Keynes, 1989; Fraser et al. 1990; Figdor and Stern, 1991). Given that the restricting boundaries are not visible and that they require the presence of the adjacent somites for their maintenance, we might speculate on the mechanisms that restrict the spread of the clones within the ventrolateral neural tube.

In the accompanying paper (Lim et al. 1991), we showed that the myelomeres of the trunk neural tube depend on the continued presence of adjacent somites; for example, if the somites are shifted by heat shock (Primmett etal. 1988), the myelomeres also shift. In this paper we show that clones derived from cells situated opposite the middle of a somite tend to expand along the mediolateral axis, while clones derived from cells opposite unsegmented mesoderm tend to expand along the rostrocaudal axis. We also find that clones spread along this axis even if they are derived from older (more rostral) cells, provided that the neural tube in the region of the clone is not adjacent to segmented mesoderm. Mechanical interactions with the adjacent mesodermal somites were proposed to explain the existence of myelomeres (Lim et al. 1991). A similar mechanism might underlie the alignment between lineage restriction units and the adjacent somitic mesoderm revealed in the present study: when a somite appears, the resulting pressure could prevent mitotic spindles from being aligned along the line of greatest stress, opposite the middle of the apposed, spherical somite. Such a reorientation of mitotic spindles might prevent the accumulation of daughter cells at that site.

The presence of lineage restrictions in the spinal cord raises the question whether the expression patterns of genes or their products are similarly restricted during the early development of the neural tube. Of the many published studies of homeobox gene expression during early mouse development (see Holland, 1990), none has described periodic expression patterns in the spinal cord. Instead, some studies demonstrate the existence of rostral boundaries of expression within the spinal cord. For example, the rostral boundary of expression for Hox 2.5 is at the level of the 3rd cervical vertebral segment (Graham et al. 1989; Bogarad et al. 1989), that for Hox 3.2 is T3 (Erselius et al. 1990) and that for Hox 5.2 lies at T10 (Duboule and Doll, 1989). Such patterns raise the possibility that the rostral boundaries of Hox gene expression within the spinal cord may correspond to the lineage restriction boundaries described in the present study. However, the significance of both the domains of gene expression and of lineage restriction boundaries for the development and function of the spinal cord remains to be established.

Although the presence and pattern of myelomeres is dependent on the segmentation of the adjacent mesoderm, the resulting clonal boundaries may play a role in the development of the neuronal pattern. For example, clonally related motoneurones may make related central connections. In such a scheme, $3 / 4$ of the motoneurones of each segmental nerve would be related to one another and $1 / 4$ would be related to those of the next segment (Fig. 5). Further research will

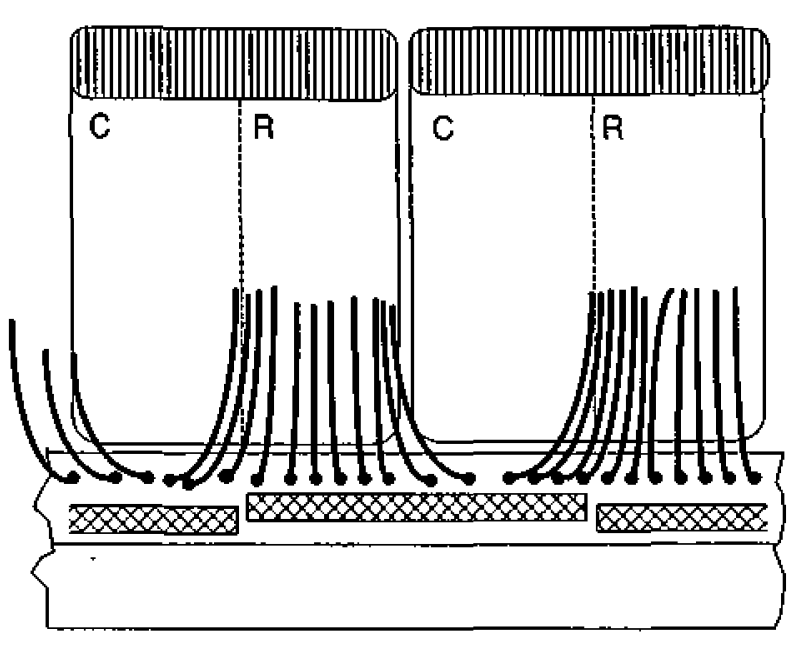

Fig. 5. Scheme illustrating the relationship between the position of motor neurone cell bodies that innervate the rostral half of a somite with their clonal origins. The diagram shows two adjacent somites and the neural tube. Axons that enter the rostral half $(\mathrm{R})$ of a somite arise from cell bodies about half of which arise from the adjacent region of neural tube, one quarter from the region opposite the caudal half $(\mathrm{C})$ of the preceding somite and one quarter from opposite the caudal half of the same somite. However, clonal restrictions arising during segmentation of the adjacent somitic mesoderm define polyclonal regions of ventral neural tube (shown as hatched rectangles), which extend from the middle of one adjacent somite to the middle of the next. This scheme generates three periodicities in the somite-neural tube complex, out of phase with each other by one quarter of one somitelength. The somites themselves, the motor neurone pool that innervates a single rostral half (out of phase with the latter by a quarter-somite) and the polyclonal units from which these motor axons arise, out of phase with the units of motor neurone cell bodies by a quarter-somite.

be required to establish whether a disturbance in the lineage relationships between motoneurones in a segment affects the pattern or precision of central connections established by these motoneurones.

This study was funded by grants from the Medical Research Council (CDS, RJK), from the NIH to SEF and by a travel grant from the Wellcome Trust to CDS. The confocal microscope was purchased with a grant from the Medical Research Council.

\section{References}

BOGARAD, L. D., UTSET, M. F., AWCULEWITSCH, A., MIKI, T., HART, C. P. AND RUDDLE, F. H. (1989). The developmental expression pattern of a new murine homeobox gene: Hox-2.5. Devi Biol. 133, 537-549.

DUBOULE, D. AND DOLL, P. (1989). The structural and functional organization of the murine Hox gene family resembles that of Drosophila homeotic genes. EMBO J. 8, 1497-1515.

ERSELIUS, J. R., GOULDING, M. D. AND GRUSS, P. (1990).

Structure and expression pattern of the murine Hox-3.2 gene. Development 110, 629-642.

FIGDOR, M. C. AND STERN, C. D. (1991). Segmental organisation of the diencephalon during vertebrate development, (submitted). 
FRASER, S., KEYNES, R. AND LUMSDEN, A. (1990). Segments in the chick embryo hindbrain are defined by cell lineage restrictions. Nature 344, 431-435.

GRAHAM, A., PAPALOPULU, N. AND KRUMLAUF, R. (1989). The murine and Drosophila homeobox gene complexes have common features of organisation and expression. Cell 57, 367-378.

HAMBURGER, V. AND HAMILTON, H. L. (1951). A series of normal stages in the development of the chick. J. Morph. 88, 49-92.

HOLLAND, P. W. H. (1990). Homeobox genes and segmentation: co-option, co-evolution, and convergence. Seminars Devi Biol. $1,135-145$.

KEYNES, R. J. AND STERN, C. D. (1988). Mechanisms of vertebrate segmentation. Development 103, 413-429.

LEBER, S. M., BREEDLOVE, S. M. AND SANES, J. R. (1990). Lineage, arrangement, and death of clonally related motoneurons in chick spinal cord. J. Neurosci. 10, 2451-2462.

LIM, T. M., JAQUES, K. F., STERN, C. D. AND KEYNES, R. J.
(1991). An evaluation of myelomeres and segmentation of the chick embryo spinal cord. Development 113, 227-238.

LUMSDEN, A. G. S. AND KEYNES, R. J. (1989). Segmental patterns of neuronal development in the chick hindbrain. Nature 337 , $424-428$.

PRIMMETT, D. R. N., STERN, C. D. AND KEYNES, R. J. (1988) Heat-shock causes repeated segmental anomalies in the chick embryo. Development 104, 331-339.

STERN, C. D., FRASER, S. E., KEYNES, R. J. AND PRIMMETT, D. R. N. (1988). A cell lineage analysis of segmentation in the chick embryo. Development 104 (Supplement), 231-244.

STERN, C. D. AND KEYNES, R. J. (1987). Interactions between somite cells: the formation and maintenance of segment boundaries in the chick embryo. Development 99, 261-272.

\{Accepted 28 May 1991) 